Bangladesh J. Bot. 49(3): 481-486, 2020 (September)

\title{
AUTO-EXHAUST POLLUTION EFFECTS ON THE LEAF STRUCTURE OF OLEA EUROPEA L.
}

\author{
Ilkay ÖZtürk Çali* aNd NeSlihan KaRavin \\ Department of Biology, Faculty of Arts and Science, Amasya University, \\ Amasya-05100, Turkey
}

Keywords: Auto-exhaust, Pollution effects, Leaf structure, Olive

\begin{abstract}
Effects of auto-exhaust pollution on the leaf structure of Olea europea L. (Olive) were determined. Olive leaves were collected from three areas, such as, no low and heavy traffic areas with different traffic intensity. Anatomical layer thickness of leaves was studied in cross sections. Results showed that, the least values of layer thickness of leaves and total leaf thickness were obtained from high traffic area. Auto-exhaust pollution caused chlorosis and necrosis in morphological structure of olive leaves as well. The plant tolerated traffic-based pollution stress by decreasing anatomical layer thickness, however chlorosis occurred. Therefore, olive leaves can be used as a bio-indicator for traffic-based pollution because of their higher sensitivity to exhausts gases.
\end{abstract}

\section{Introduction}

In recent years, air pollution is an important problem all over the world particularly in many thickly populated and industrialized areas (Kambezidis et al. 1996). According to WHO (2006), in many urban areas of the world, traffic-based pollution is a major source of air pollution contributing $57-75 \%$ of total emissions. The increasing number of motor vehicles is continuously adding toxic gases and other substances to the environment. Metals are one of the most harmful materials that are caused by from auto-exhaust pollution. Metals from exhausts gases and mechanical parts of motor vehicles tend to accumulate in plant tissues and have detrimental effects on the metabolism of roadside plants even before visible symptoms appear (Viskari et al.2000, Karavin and Ural 2016). Many researchers stated that road traffic emissions caused some changes on the morphology and foliar anatomy of roadside plants (Ghouse et al. 1980, Jahan and Iqbal 1992, Pandey and Agrawal 1994, Verma et al. 2006, Joshi and Abhishek 2007). Some parts of substances deposit on plant surface and the other parts of them penetrate into plant tissues. Roadside plant leaves can be generally covered with motor exhaust particulates which cause decrease in the capacity for photosynthesis (Woolhouse 1986).

Olive tree (Olea europaea L.) is the most important fruit trees in Mediterranean countries, because of its economical value. The fruits and the oil of olive tree are used in the daily nourishment of a large part of the world's population. The leaves of olive have the secoiridoid compounds, oleacein and oleuropein named secondary metabolites. These leaves were used for medicinal purpose; therefore, olive leaves have important role (Hansen et al. 1996). Many researchers reported that olive leaf extract has the capacity to lower blood pressure in animals (Samuelsson 1951) and increase blood flow in the coronary arteries (Zarzuelo et al. 1991), relieve arrhythmia and prevent intestinal muscle spasms (Garcia et al. 2000). Unfortunately, auto-exhaust pollution can damage leaves, fruits of olive trees and this kind of pollution limits the factors for olive productivity. For this reason, olive tree leaves are used as a bio-indicator for environmental pollution in Aydin, a city in western Turkey (Turan et al. 2011).

*Author for correspondence: <ilkaycali@ hotmail.com>. 
The aim of the study was to study effects of auto-exhaust pollution on the leaf structure of Olea europaea L. It was hypothesized that auto-exhaust pollution may cause damages in morphological and anatomical features in Olea europaea L. leaves because traffic-based substances may deposit on leaf surface and metals may accumulate in leaves.

\section{Materials and Methods}

The experiment was carried out in Botanical Laboratory of Biology Department, Faculty of Art and Science, Amasya University. The study was carried out by using leaf samples of Olea europaea L. (Olive) collected from olive trees in three different areas where there is no traffic (rural area- Buca Kaynaklar village), less-traffic (inside of Evka 3) and heavy-traffic (Evka 3 roadside) in İzmir which is a megacity in western Turkey.

The leaf samples were collected from 10 olive trees in each area. In order to reflect all the canopy leaf samples were collected from bottom, middle and top. Leaf samples were fixed in $70 \%$ ethyl alcohol for anatomical investigation. In order to investigate morphological effects of trafficbased pollution on olive leaves, morphological observation on leaves belonging to each groups was used and necessary parts were photographed. Hand-made cross sections in leaves were obtained to determine the anatomical layer thickness of leaves. Transverse sections for anatomical observation of leaves were made by hand using commercial razor blades. Sartur reagent was applied to the sections for investigation of some anatomical tissues easily (Çelebioğlu and Baytop 1949). A Leica ICC50 HD binocular light microscope, a Leica Digital Camera and X10 - X40 objectives were used for the measurements of the width-length measurements in various tissues. Preparations were photographed with a Leica ICC50 HD binocular light microscope and a Leica Digital Camera.

SPSS 20.0 for Windows was used as statistical analysis. The variance analyses were made by using the Tukey test.

\section{Results and Discussions}

Metal pollution-based traffic not only leads to physiological damages in plants, but it also affects morphological and anatomical structures of plants. The values of width-length measurements of leaf anatomical layers in transverse sections belonging to each group are presented in Table 1. All results in width-length measurements of leaf anatomical layers were lower in less and heavy traffic areas than in rural area. Such a decrease in width-length measurements of leaf anatomical layers seen in less and heavy traffic areas was statistically significant as compared to the rural area. Specially, the decrease in values of width-length measurements of palisade and spongy parenchyma is very important, because photosynthetic reaction occurs in the mesophyll layer of leaves. Therefore, photosynthesis, which is the most important physiological process in leaves, can be affected negatively. It was also found that the values of total palisade and spongy area were lower in less and heavy traffic areas than rural area. The least total area of palisade parenchyma was seen in heavy traffic area clearly (Fig. 1e). Regional deformations and breakdown in palisade cells belonging to heavy traffic area were observed as well (Fig.1e). Besides, the values of width-length measurements of midrib trachea were lower in less and heavy traffic areas than rural area and the least thickness of midrib trachea was determined in areas with heavy traffic. Decrease was seen in total leaf thickness according to increase in traffic density. To sum up, accumulation of $\mathrm{Cd}, \mathrm{Cr}$ and $\mathrm{Co}$ metals in high concentrations caused by vehicle exhausts can give rise to a decrease in all anatomical layer thicknesses of olive leaves. 


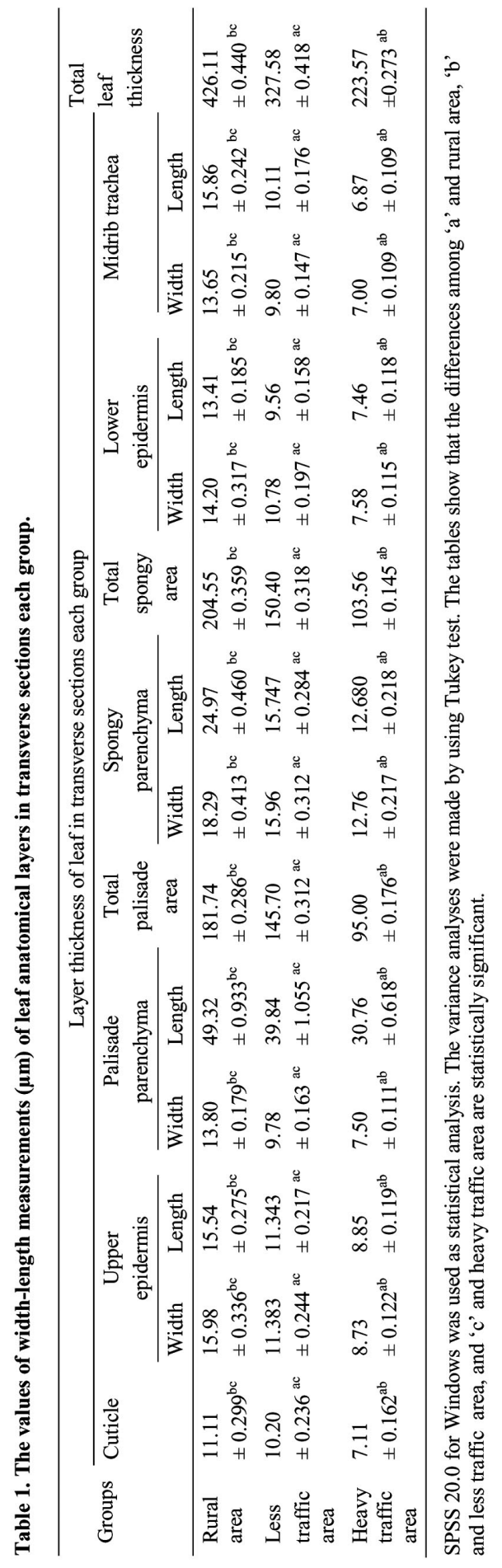


There are many reports on morphological, physiological and anatomical changes in plants due to polluted conditions (Inamdar and Chaudhari 1984, Iqbal 1985, Gupta and Ghouse 1988, Gravano et al. 2003, Novak et al. 2003 and Dineva 2004). Vehicles in the traffic are the main sources of pollution in urban atmosphere of İzmir. The lead pollution caused by vehicles on the leaf anatomy of pine leads decreasing the leaf diameter, tracheid diameter, epidermis cell number and size, stomata number, width and index (Çavuşoğlu et al. 2009). There was a reduction in width-length and total area of leaves in various plant species exposed to exhaust gases (Jahan and Iqbal 1992). Besides, these researchers also mentioned that a reduction occurred in cuticle, the cells
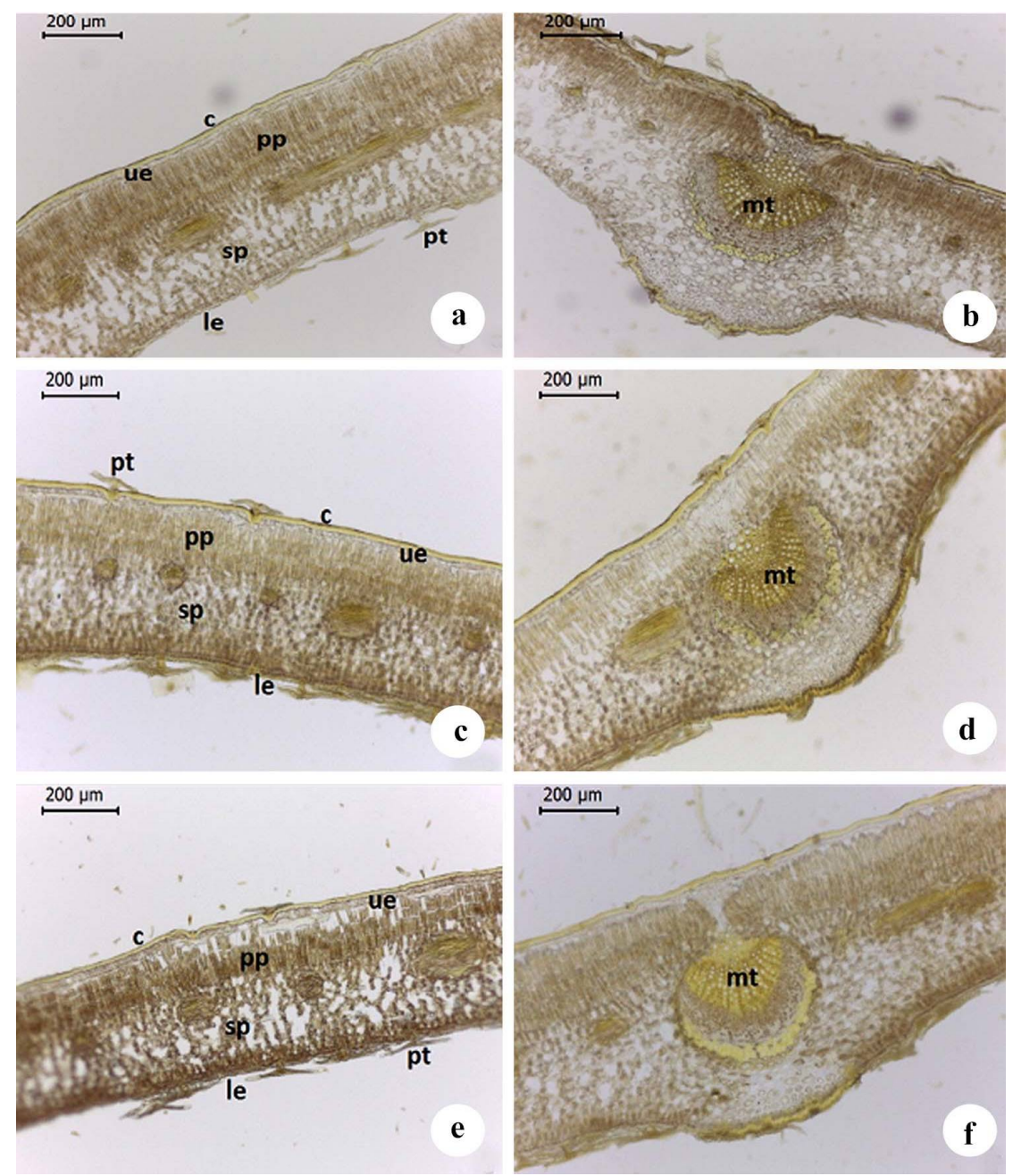

Fig. 1. Transverse sections of leaves in rural area (a, b), in less traffic area (c, d) and in heavy traffic area (e, f). c: cuticle, ue: upper epidermis, pp: palisade parenchyma, sp: spongy parenchyma, le: lower epidermis, pt: peltate trichome and mt: midrib trachea.

of epiderma, palisade and parenchyma. Similarly, the heavy metal applications to plants caused significant reduction of lamina and mesophll thickness (Kovacevic et al. 1999). The results in the present study are in agreement with those of Jahan and Iqbal (1992) and Kovacevic et al. (1999). In the present study, the observation of reduced anatomical layer thickness may be a plant 
adaptation to changing environmental factors to reduce accumulated metals caused by trafficbased pollutants. This adaptation can help plants minimize stress and maximize use of internal and external resources (Dineva 2004).

When it comes to the effects of traffic-based pollution on morphological features of olive leaves, it was found that chlorosis and necrosis were on leaves in both traffic areas (Fig. 2). No leaves were observed in the rural area whereas the highest chlorosis and necrosis levels were observed on the leaves in heavy traffic area. In this study, chlorosis and necrosis situations increased in parallel with traffic intensity. Several pollutants can cause some changes such as necrosis in leaf and chlorosis morphology when compared to unpolluted condition (Heath 1980). Particularly, the leaves applied heavy metal of plants are smaller and chlorotic (Khan and Khan 1983). In addition to this, chlorotic leaves show reduction in photosynthesis (Yun 2007). In the present study, the highest chlorosis and necrosis levels were observed in heavy traffic area, therefore it may be said that photosynthesis level could be reduced in heavy traffic area due to chlorosis. Besides, it was reported that $\mathrm{Cd}$ toxicity-based traffic pollution caused negative effects in leaf structure, particularly this kind of toxicity resulted in scorching of leaf tip (Shanker et al. 2005). Therefore, observation of necrosis in this study can result from $\mathrm{Cd}$ accumulation-based traffic pollution.
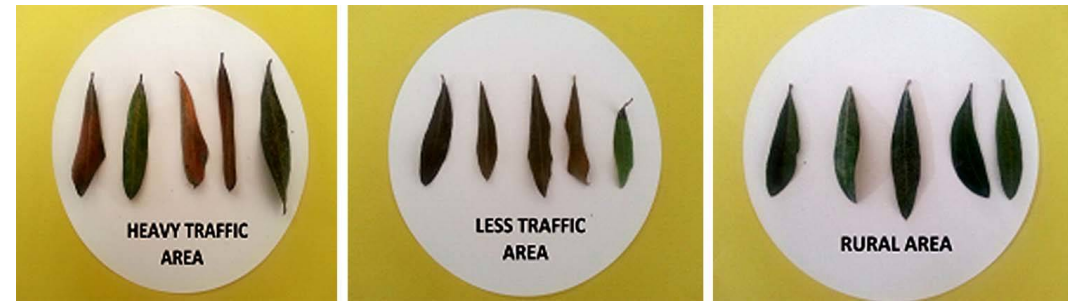

Fig. 2. The effect of traffic-based pollution on morphological features of olive leaves. Chlorosis and necrosis are seen on leaves in both traffic areas.

It may be concluded that auto-exhaust pollution caused negative effects on the anatomy and morphology structures on olive leaves. Reduced anatomical layer thickness, chlorosis and necrosis in morphological structure in heavy traffic area were determined. Regional deformations and breakdown in palisade cells belonging to heavy traffic area have been observed.

\section{Acknowledgements}

This study was financially supported by the authority of Amasya University BAP unit with project FMB-BAP-034.

\section{References}

Çavuşoğlu K, Kılıç S and Kılıç M 2009. Effects of lead (Pb) pollution caused by vehicles on the anatomy of pine (Pinus nigra Arn. subsp. pallasiana) and cedar (Cedrus libani A. Rich.) leaves. BioDiCon. 2(3): 92-98.

Çelebioğlu S and Baytop T 1949. A new reagent for microscopical investigation of plant. Publication of the Inst. of Pharmacog. 10: 300-301.

Dineva S 2004. Comparative studies of the leaf morphology and Willd. growing in polluted area. Dendrobiol. 52: 3-8.

Garcia OB, Castillo J, Lorente J, Ortuno A and Del-Rio JA 2000. Antioxidant activity of phenolics extracted from Olea europaea L. leaves. Food Chem. 68: 457-462.

Ghouse AKM, Zaidi H and Attique A 1980. Effect of air pollution on the foliar organs of Callistemon citrinus. Stapf. J. Sci. Res. 2: 207-209. 
Gravano E, Gilnlietti V, Desotgiu R, Bussotti F, Grossoni P, Gerosa G and Tani C 2003. Foliar response of an Ailanthus altissima clone in two areas with different levels of ozone-pollution. Environ. Pollut. 121(1): 137-146.

Gupta MC and Ghouse AKM 1988. Effects of coal smoke pollutants from different sources in the growth, chlorophyll content, stem anatomy and cuticular traits of Euphorbia hirta L. Environ. Pollut. 47: 221230.

Hansen K, Adsersen A, Christensen BS, Brooegger S, Rosendal JS, Nyman U and Smitt UV 1996. Isolation of an angiotensin converting enzyme (ACE) inhibitor from Olea europaea and Olea lancea. Phytomed. 2: 319-324.

Heath RL 1980. Initial events in ingury to plants by air pollutants. Annu. Rev. Plant Physiol. 31: 395-491.

Inamdar JA and Chaudhari GS 1984. Effect of environmental pollutants on leaf epidermis and leaf architecture of Peristrophe bicalyculata. J. Plant Anat. and Morph. 1: 1-8.

Iqbal MZ 1985. Cuticular and anatomical studies of white clover leaves from clean and air-polluted areas. Pollut. Res. 4: 59-61.

Jahan S and Iqbal MZ 1992. Morphological and anatomical studies of leaves of different plants affected by motor vehicles exhaust. J. Islamic Acad. Sci. 5: 21-23.

Joshi PC and Abhishek S 2007. Physiological responses of some tree species under roadside automobile pollution stress around city of Haridwar, India. Environment 27: 365-374.

Kambezidis HD, Adamopoulos AD and Gueymard C 1996. Total $\mathrm{NO}_{2}$ column amount over Athens, Greece in 1996-97. Atmos. Res. 57: 1-8.

Karavin N and Ural Z 2016. Impact and Extent of Traffic-Based Pollution on N and P Use Proficiency and Litter Decomposition in Malus domestica Borkh. Water Air Soil Pollut. 227(6): 1-10.

Khan DH and Khan NN 1983. Influence of lead and cadmium on the growth and nutrition concentration of tomato (Lycopersicum esculentum L.) and eggplant (Solanum melongena L.). Plant Soil 74: 387-394.

Kovacevic G, Kastori R and Merkulov LJ 1999. Dry matter and leaf structure in young wheat plants as affected by cadmium, lead and nickel. Biol Plant 42(1): 119-123.

Novak K, Skelly J, Schaub M, Kraeuchi V, Hug C, Landlot W and Bleuler P 2003. Ozone air pollution and foliar injury onnative plants of Switzerland. Environ Pollut. 125 (1), 41-52.

Pandey J and Agrawal M 1994. Evaluation of air pollution phytotoxicity in a seasonally dry tropical urban environment using three woody perennials. New Phytol. 126: 53-61.

Samuelsson G 1951. The blood pressure lowering factor in leaves of Olea europaea. Farmacevtisk Revy. 15: 229-239.

Shanker AK, Cervantes C, Loza-Tavera H and Avudainayagam S 2005. Chromium toxicity in plants. Environ. Int. 31(5), 739-753.

Turan D, Kocahakimoglu C, Kavcar P, Gaygisiz H, Atatanir L, Turgut C and Sofuoglu SC 2011. The use of olive tree (Olea europaea L.) leaves as a bioindicator for environmental pollution in the Province of Aydin, Turkey. Environ. Sci. Pollut. R. 18: 355-364.

Verma RB, Mahmooduzzafar N, Siddiqui TO and Iqbal M 2006. Foliar response of Ipomea pes-tigridis L. to coal-smoke pollution. Turk. J. Bot. 30: 413-417.

Viskari EL, Surakka J, Pasanen P, Mirme A, Kössi S, Ruuskanen J and Holopainen JK 2000. Responses of spruce seedlings (Picea abies) to exhaust gas under laboratory conditions. I Plant-insect interactions. Environ. Pollut. 107: 89-98.

WHO 2006. Air quality guidelines for particulate matter. Ozone, Nitrogen Dioxide and Sulphur Dioxide, Global Update 2005, WHO Regional Office for Europe, Copenhagen, Denmark.

Woolhouse H 1986. Procesa and control of plant senescence. In: Leshem YY, Halvey AW, Frankel C (eds). pp. 3-20. Elsevier Science Publisher, Netherlands.

YUN M 2007. Effect of ozone on $\mathrm{CO}_{2}$ assimilation and PSII function in plants with contrasting. Pollutant Sensitivities, Dissertation, Virginia Polytechnic Institute and State University.

Zarzuelo A, Duarte J, Jimenez J, Gonzales M and Utrilla MP 1991. Vasodilator effect of olive leaf. Planta Med. 57: 417-419.

(Manuscript received on 22 October, 2018; revised on 11 June, 2019) 